\title{
nature physics
}

\section{A new year, a new look: Nature Physics has fresh page designs and fresh content to take you into 2007, and beyond...}

As you turn the pages of this, the first issue of Volume 3 of Nature Physics, you might notice some changes. Many of the sections of the journal, among the research papers and the magazine material, have a new look. Where once there were two columns, there may now be three; text that was once unjustified may now be justified. We've taken a hard look at the space available on the pages of Nature Physics, and have come up with a new way to use it, to its full extent.

There is now less white space - and more physics. In News \& Views, in particular, we have instituted a 'run-on' of the articles, also improving its magazine feel. And we've included some extra short pieces in the make-up of the section. Alongside the regular News \& Views articles and our Research Highlights page, these items serve to widen still further our coverage of the physics literature.

Most of the changes in this issue are purely cosmetic, but with a couple of exceptions: we have some new content to offer too. We are pleased to welcome David Goodstein, of the California Institute of Technology, as a regular contributor to our Thesis section, taking over the mantle from Lawrence Krauss. Alongside Mark Buchanan's monthly ruminations on physics, David will be offering his opinion, as Lawrence before him, on a range of issues that physicists - in the lab and at large in society - face today.

And we have a new feature on the back page of the issue (although online readers might be hazy about which is the 'back page'). Since our launch in October 2005, 'Endgame' on the back page has featured a series of images of historical scientific apparatus, from London's Science Museum, each offered with a clue to its provenance and with an informative solution from Science Museum curators following in the next month's issue. The collection included Kelvin's tide machine, the Lawrence-Livingston cyclotron and a seventeenth-century Italian thermometer - how many did you guess correctly?

That series is now at an end, although remains available in our online archive at www.nature.com/naturephysics. In its place, we are delighted to bring you 'Futures'. Regular readers of our sister title Nature may already be familiar with this strand of science-fiction essays - winner of a European Science Fiction Society award - which ended its run in Nature, on the back page, last month. In 2007, a specially commissioned physics-based series of Futures essays will grace the back page of Nature Physics.

Does science fiction have a place in a journal of science fact? Futures is about imagination, communication, extrapolation, lateral thinking - and physics. On that basis, we think it comfortably makes the grade. Most of all, it's there to be enjoyed. As ever, your feedback is welcome - get in touch at naturephysics@nature.com.

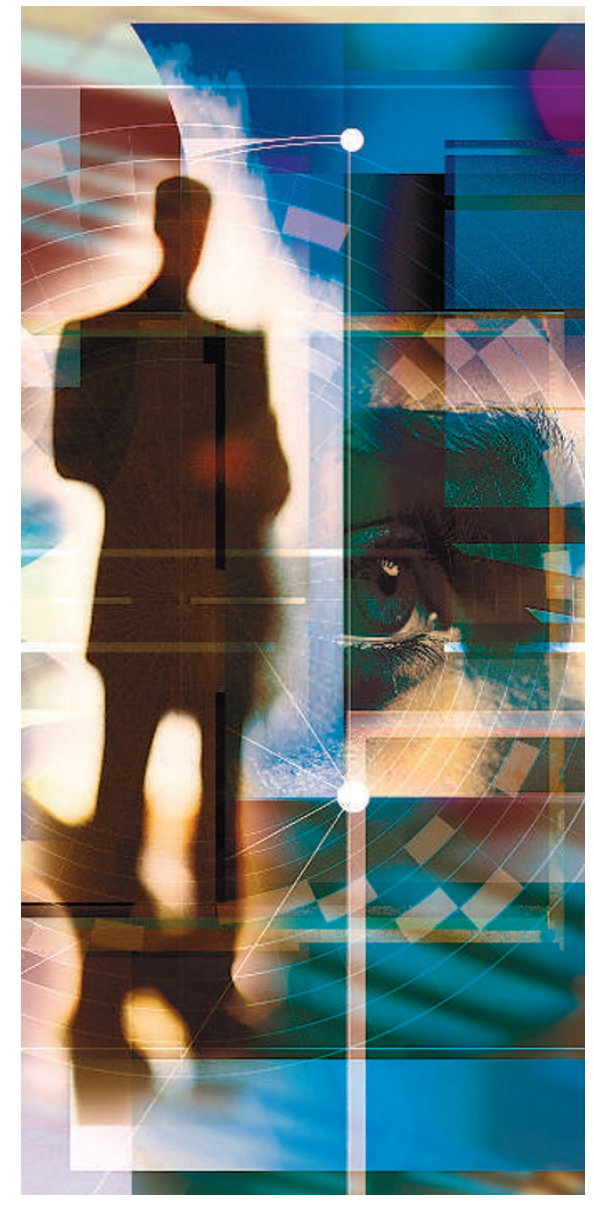

The future is... - find out on the back page. 